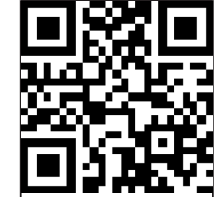

Editor's choice can to access mo free content
- Additional materials are published online only. To view these files please visit the journal online (http://dx.doi.org/ 10.1136/gutjnl-2011-300384).

${ }^{1}$ Institute of Clinical Molecular Biology, Christian-Albrechts University, Kiel, Germany ${ }^{2}$ Institute of Biochemistry, Christian-Albrechts University, Kiel, Germany

${ }^{3}$ Department of Internal

Medicine I, University Hospital Schleswig-Holstein

Christian-Albrechts University, Kiel, Germany

\section{Correspondence to}

Dr Stefan Schreiber, Professor of Medicine and

Gastroenterology, Department of General Internal Medicine, Schittenhelmstr.12, University Hospital Schleswig-Holstein, Campus Kiel, 24105 Kiel,

Germany;

s.schreiber@mucosa.de

PCR and SS share scientific responsibility and senior authorship.

Revised 13 February 2012 Accepted 16 February 2012

Published Online First

25 April 2012

\title{
mTNF reverse signalling induced by TNF $\alpha$ antagonists involves a GDF-1 dependent pathway: implications for Crohn's disease
}

\author{
Stefanie Derer, ${ }_{1}^{1}$ Andreas Till, ${ }^{1}$ Robert Haesler, ${ }^{1}$ Christian Sina, ${ }_{1}^{1}$ Nils Grabe, ${ }^{1}$ \\ Sascha Jung, ${ }^{2}$ Susanna Nikolaus, ${ }^{3}$ Tanja Kuehbacher, ${ }^{3}$ Joachim Groetzinger, ${ }^{2}$ \\ Stefan Rose-John, ${ }^{2}$ Philip C Rosenstiel, ${ }^{1}$ Stefan Schreiber ${ }^{1,3}$
}

\section{ABSTRACT}

Objective Mechanisms of action (MoA) of anti-tumour necrosis factor $\alpha$ (TNF $\alpha$ ) therapies in Crohn's disease (CD) may critically involve induction of immune cell apoptosis via membrane-bound TNF $\alpha$ (mTNF $\alpha$ ) binding. Certolizumab pegol (CZP), which is effective in induction and maintenance of remission in CD lacks the ability to induce apoptosis. The aim of this study was to analyse transcriptomal responses of reverse signalling induced by the TNF $\alpha$ binding agents infliximab (IFX) and CZP in myelomonocytic cells.

Design Induction of transcriptional patterns upon antiTNF $\alpha$ stimulation was assessed using oligonucleotide microarrays. mRNA expression of GDF-1/ LASS1, which was identified as a shared target, was studied in inflammatory bowel disease by real-time PCR, while signalling pathways induced by growth and differentiation factor 1 (GDF-1) were investigated using western blots and ELISA.

Results IFX and CZP induced a common signature of 20 transcripts that could be categorised into control of cell cycle, transcription activation and pre-mRNA processing We selected GDF-1/LASS1 for functional follow-up, which was found to be upregulated in inflamed CD tissues. We show that downregulation of GDF-1/LASS1 depends on autocrine release of transforming growth factor $\beta$ after mTNF $\alpha$ ligation. We demonstrate that GDF-1 itself acts as a novel proinflammatory factor via induction of interleukin 6 and signal transducer and activator of transcription 3 and is downregulated after IFX treatment.

Conclusion Commonalities in the MoA of IFX and CZP comprise modulation of non-apoptotic pathways through downregulation of proinflammatory GDF-1. Further characterisation of the molecular role of GDF-1 in complex inflammatory processes in vivo is warranted to decide whether this proinflammatory molecule is a promising therapeutic target in patients with CD.

\section{INTRODUCTION}

As many as 1.4 million people in the USA and 2.2 million in Europe have inflammatory bowel disease (IBD), a lifelong disease that can be differentiated into two major sub-phenotypes, Crohn's disease (CD) and ulcerative colitis (UC). The pathophysiology of IBD is characterised by a highly activated state of the mucosal immune system and excessive

\section{Significance of this study}

What is already known on this subject?

- Infliximab (IFX) and certolizumab pegol (CZP) are effective in the therapy of Crohn's disease (CD).

- IFX but not CZP induces apoptotic pathways.

- Transforming growth factor $\beta$ (TGF $\beta$ ) has been shown to be induced by IFX.

What are the new findings?

- Mechanisms of action of IFX and CZP comprise modulation of non-apoptotic pathways through downregulation of proinflammatory signals via growth and differentiation factor 1(GDF-1).

- Downregulation of GDF-1 by IFX and CZP depends on autocrine release of $\operatorname{TGF} \beta$ after membrane-bound tumour necrosis factor $\alpha$ ligation.

- GDF-1 acts as a proinflammatory factor via induction of interleukin 6 and signal transducer and activator of transcription 3.

- GDF-1 is upregulated in inflamed tissues from patients with CD.

- GDF-1 is downregulated after IFX treatment in patients whose condition responds to IFX

How might it impact on clinical practice in the foreseeable future?

- Studying the exact physiological role of GDF-1 in complex inflammatory processes in vivo may answer the question of whether this proinflammatory molecule could be a novel promising target in the therapy of patients with CD.

mucosal destruction. Although the aetiology is unknown, it is assumed that IBD is a multifactorial disease caused by the interplay of genetic, environmental and immunological factors. Despite advances in the understanding of the complex and diverse early events of disease precipitation, a pathophysiological hallmark of the inflammatory processes observed in $\mathrm{CD}$ is the preponderance of the proinflammatory cytokines, for example, tumour necrosis factor $\alpha(\mathrm{TNF} \alpha)$, interleukin 6 (IL6 ) and IL-12, which play critical roles in the initiation and perpetuation of inflammation in $\mathrm{CD}$. $\mathrm{TNF} \alpha$ is an important mediator of inflammatory 
processes and is likely to be at the apex of the inflammatory cascade in $\mathrm{CD},{ }^{1}$ as it is increased in intestinal tissue and stools of patients with CD. Clinical evidence for efficacy of systemic inhibition of TNF $\alpha$ is given by the fact that a single infusion of a chimeric monoclonal anti-TNF $\alpha$ antibody (infliximab, IFX) has been shown to induce remission and significantly improve clinical symptoms in patients with CD in multiple studies. ${ }^{2} 3$

TNF $\alpha$ secretion represents a complex process by which membrane-bound TNF $\alpha$ (mTNF $\alpha$ ) is expressed and then cleaved by TNF $\alpha$-converting enzyme. ${ }^{4}$ It was reported that ligands of the TNF superfamily could act as receptors and are able to elicit bidirectional signals ('reverse signalling'), ${ }^{5}$ whereas systematic knowledge about the impact of therapeutically administered TNF $\alpha$ binding proteins on reverse signalling via mTNF $\alpha$ is still missing. ${ }^{6}$ We have previously shown that infliximab transiently activates the p38 mitogen-activated protein kinase (MAPK) and p44/42 extracellular signal-regulated kinase (ERK1/2) in monocytic cells in vitro and in vivo. A differential phosphorylation of p38 MAPK was observed in patients with CD who respond and do not respond to infliximab therapy. ${ }^{7}$ Reverse signalling events via $\mathrm{mTNF} \alpha$ led to an enhanced secretion of transforming growth factor $\beta$ (TGF $\beta$ ), which in turn was responsible for the activation of p38 and ERK1/2 and the induction of apoptosis via caspase $3{ }^{8}$ Further in vivo and in vitro studies also reported caspase-dependent and therefore pro-apoptotic effects of infliximab on peripheral blood mononuclear cells (PBMCs) and T cells. In contrast, the anti-TNF $\alpha$ compound etanercept, a recombinant TNFR2:Fc fusion protein, failed to induce apoptosis in peripheral and lamina propria lymphocytes ${ }^{9}$ and also did not induce clinical remission in patients with CD. ${ }^{10}$ Therefore, induction of apoptosis was thought to be a critical mechanism of action of anti-TNF $\alpha$ therapy in active CD. ${ }^{9} 11$ This theory has been questioned since certolizumab pegol (CZP), a pegylated Fabfragment without IgG-Fc, has been shown to be clinically effective in CD but does not induce apoptosis. ${ }^{11}{ }^{13}$ Taken together, the previous studies suggest a complex intracellular signalling cascade downstream of the engagement of mTNF $\alpha$ by anti-TNF $\alpha$ compounds.

We systematically compared transcriptomal signatures elicited by the therapeutic TNF $\alpha$-binding molecules CZP and IFX in myelomonocytic cells to characterise unique and shared molecular mechanisms that may help to explain the clinical efficacy of these agents in the therapy of $\mathrm{CD}$. Whole genome expression screening in THP-1 cells, a human monocytic leukemia cell line, revealed 20 transcripts, which are significantly coregulated by IFX and CZP. Among these we characterised the growth and differentiation factor 1 (GDF-1), a member of the TGF $\beta$ superfamily, as a novel proinflammatory mediator, which is regulated by anti-TNF $\alpha$ agents.

\section{MATERIALS AND METHODS Study population}

There were four different patient cohorts in this study. Samples were categorised by the following abbreviations: hospitalised normals (HN), patients with CD and no inflammation (CD_ni), patients with $\mathrm{CD}$ and active inflammation ( $\mathrm{CD}_{-} \mathrm{i}$ ), patients with UC and no inflammation (UC_ni), patients with UC and inflammation (UC_i) and disease control patients with unspecific intestinal inflammation (DC_i).

Patient cohort I includes 109 patients: 85 patients with IBD and 24 controls for real-time PCR (RT-PCR) quantification experiments with approximately half of the samples taken from active disease in the patient groups (for detailed characterisation of all patients, see online supplementary table 1). The normal control group (HN) included 24 subjects without abnormal endoscopy findings. Group II (20 patients: 5 HN, 5 CD_i, 5 UC_i and 5 DC_i) and group III (23 patients: 3 HN, 5 CD_I, 5 CD_ni, 5 UC i and 5 UC ni) had ELISA and western blot analyses.

Group IV included 13 patients with CD with biopsies taken directly before and 1 week after infliximab therapy. Patients who showed a clinical response to IFX were defined as patients whose CD activity index (CDAI) decreased at least $70 \mathrm{CDAI}$ points 2 weeks after IFX infusion, similar to seminal clinical trials. ${ }^{314}$ Of this group, eight patients were classified as clinical responders and five were classified as clinical non-responders to IFX treatment.

Biopsies were taken from the sigmoid and active disease was defined by respective disease activity indices (CDAI $>150$, colitis activity index $(\mathrm{CAI})>4)$. Medication included 5-aminosalicylic acid, azathioprine or glucocorticoids $(<25 \mathrm{mg})$ according to the clinical requirements of the patients, but not an active biological therapeutic regime. The endoscopies were part of regular patient management. All patients agreed to participation by giving informed consent at least $24 \mathrm{~h}$ before the procedure and the study was granted prior approval by the local ethics committee.

\section{Cell culture, transfection and reagents}

All analysed cell lines were purchased from the German Collection of Microorganisms and Cell Cultures (DSMZ, Braunschweig, Germany). PBMCs were isolated from $100 \mathrm{ml}$ of peripheral blood drawn from healthy volunteers and cultured as described previously. ${ }^{15}$

For stimulation experiments, the following main stimuli were used: a monoclonal mouse-human chimeric anti-TNF $\alpha$ antibody IFX (Remicade; Centocor, Horsham, Pennsylvania, USA), an irrelevant pegylated $\left(\mathrm{Fab}^{\prime}\right)_{2}$ fragment and a pegylated $(\mathrm{Fab})_{2}$ fragment of a humanised monoclonal antibody CZP (CDP870; Cimzia; UCB, Belgium), recombinant human TGF $\beta$ (Biosource, Invitrogen, Carlsbad, California, USA) or recombinant human GDF-1 (H00002657-P01-10, Abnova, Heidelberg, Germany). An irrelevant human IgG1 antibody (Alpha Diagnostic International Inc, San Antonio, Texas, USA) served as the control antibody.

\section{Microarray quantification of gene transcripts}

THP-1 cells were plated at $1 \times 10^{6} / 2 \mathrm{ml}$, grown for $24 \mathrm{~h}$ and incubated for 6 and $24 \mathrm{~h}$ with IFX or CZP (both $10 \mu \mathrm{g} / \mathrm{ml}$ ) or were left untreated. Colonic biopsies from anti-TNF naïve CD patients prior to or after treatment with IFX were collected and snap frozen as previously described. ${ }^{16}$ Total RNA was isolated from THP-1 cells as well as from colonic biopsies according to the manufacturer's instruction (OIAGEN Inc, Valencia, California, USA). RNA integrity was verified using an Agilent Bionanalyzer (Agilent, Böblingen, Germany) according to the manufacturer's guidelines. Microarrays (Affymetrix HG U 133 plus 2.0; Affymetrix, Santa Clara, California, USA) were prepared and processed as previously described. ${ }^{17}$ After acquiring the data using Affymetrix GeneChip Command Console (AGCC), data were normalised using the robust multiarray averaging (RMA) method ( $R$, Bioconductor). For microarray analysis of THP-1 cell samples, differential expression was determined using three filter criteria: transcripts had to be present in all samples of at least one experimental group; as a relative measure for significance, we employed a rank-sum test, allowing a maximum of one outlier per measurement (for the two controls vs three treatment samples comparison presented here, a rank sum difference below seven corresponds to two or more outliers, a rank sum difference of seven corresponds to one outlier, while a rank sum difference of nine corresponds to no 
outliers); and the fold change, which was calculated based on the ratios of the medians, had to be either bigger than 1.5 or smaller than -1.5 . Genes meeting these criteria were subjected to further analysis, which was carried out using TIBCO Spotfire (TIBCO, Palo Alto, California, USA).

The microarray data (raw and normalised) were processed according to minimal information about a microarray experiment (MIAME) guidelines and submitted to Gene Expression Omnibus $^{18}$ and are accessible through GEO Series accession number GSE33585 (http://www.ncbi.nlm.nih.gov/geo/query/ acc.cgi ?acc $=$ GSE33585).

Expression data for GDF-1 was obtained from a previously published dataset in which data were normalised using the RMA method. ${ }^{16}$ Differential expression of GDF-1 within this dataset was determined using the Mann-Whitney $U$ test.

\section{mRNA isolation and reverse-transcription PCR}

Total RNA was isolated from collected cell pellets using the RNeasy kit (OIAGEN Inc) following the manufacturer's instructions. Reverse transcription was performed by using Advantage-RT-for-PCR (Clontech, Palo Alto, California, USA) and expression of target genes and the reference transcript G3PDH was assayed by using standard PCR procedures ${ }^{15}$ and sequence-specific primers (online supplementary table 3). PCR reactions were amplified using a thermo cycler (Gene Amplification PCR System 9700, Perkin Elmer, Applied Biosystems, Foster City, California, USA). For each gene, the number of cycles was chosen directly above the detection threshold.

\section{TaqMan real-time PCR}

GDF-1/LASS1 mRNA transcript levels were measured using quantitative RT-PCR. cDNA was arrayed on 384-well plates using the expression assay Hs00242151 m1 (Applied Biosystems), which detects exon boundary 3-4 in the open reading frame of GDF-1/LASS1 on the ABI Prism 7900HT Sequence Detection System (Applied Biosystems) according to the manufacturer's protocols. Relative transcript levels were determined using the standard curve quantisation method and $\beta$ actin as the endogenous control gene.

\section{Determination of viable cell mass}

The CellTiter 96 non-radioactive cell proliferation assay based on the reduction of MTS (3-(4,5-Dimethylthiazol-2-yl)-2,5-diphenyltetrazolium bromide) by living cells was performed with THP-1 and PBMCs (20000 cells/well/100 $\mu \mathrm{l}$ in 96-well microtitre plate) according to the manufacturer's instruction (Promega Corp, Madison, Wisconsin, USA).

\section{Caspase-Glo 3/7 assay}

THP-1 cells and PBMCs were cultivated and stimulated with IFX or CZP in a microtitre plate ( 96 wells) and analysed using the Caspase-Glo 3/7 assay according to the manufacturer's instructions (Promega Corp).

\section{SDS-PAGE and immunoblotting}

Sodium dodecyl sulfate polyacrylamide gel electrophoresis (SDSPAGE) and immunoblotting experiments with whole protein lysates isolated from cell lines or colonic biopsy samples were performed as previously described (for antibodies see online supplementary table 4). ${ }^{15}$

\section{ELISA}

Supernatants of cell cultures were collected for measurement of secretion of IL-1 $\beta$ and IL- 6 by specific ELISA (BioSource Europe S.A., Nibelles, Belgium) according to the manufacturer's protocol
For human GDF-1 and TGF $\beta$ ELISA, colonic biopsy samples were collected from patients with CD and UC $(n=20)$, and from hospitalised patients $(n=3)$ and lysed according to the manufacturer's instructions using native lysis buffer (Cell Signaling Technology, Inc, Danvers, Massachusetts, USA). ELISA experiments were performed according to the manufacturer's instructions (GDF-1 ELISA, USCN Life Science Inc, Wuhan, China; TGF $\beta$ ELISA, Invitrogen).

\section{siRNA-mediated knockdown of ACVR1C}

HEK293T cells were seeded at a density of $1 \times 10^{5} /$ well in six-well plates. Next day, transfection of cells with $25 \mathrm{nM} \mathrm{ACVR1C-}$ specific small interfering RNA (siRNA) or $25 \mathrm{nM}$ of negative control siRNA for $24 \mathrm{~h}$ was carried out using Lipofectamine2000 (Invitrogen) according to the manufacturer's manual. PBMCs were transfected with $300 \mathrm{nM}$ siRNA for $24 \mathrm{~h}$ by electroporation using $1 \times 10^{7}$ cells/sample and the Amaxa Human T cell Nucleofector Kit (Lonza, Walkersville, Maryland, USA) according to the manufacturer's instructions. Synthetic siRNA targeting ACVR1C was purchased from Applied Biosystems/Ambion (Foster City, California, USA). Target sequences were as follows: ACVR1C siRNA (ID s43499) sense 5'-GGUCCUUAUAUGACUAUUtt-3 and antisense 5'-AAUAGUCAUAUAAGGAGCCct-3'. As control, unspecific siRNA Negative Control \#1 (Applied Biosystems/ Ambion) was used.

\section{Representation of data and statistical analysis}

Statistical significance was determined by the Mann-Whitney $\mathrm{U}$ test or the Wilcoxon matched pairs test (only figure 5) using GraphPad Prism 5.0 software. Results were displayed as means \pm SD. A p-value $\leq 0.05$ was considered statistically significant $\left(^{*}\right)$ and $p \leq 0.01$ was considered highly significant $\left({ }^{* *}\right)$. Experiments and measurements were replicated at least three times.

\section{RESULTS}

\section{Whole genome expression analysis}

To systematically analyse cellular responses initiated by IFX and CZP in THP-1 cells a systematic expression analysis using oligonucleotide microarrays was performed.

Using rank-sum-based statistics, a total of 1058 transcripts were regulated in which 1684 regulatory events were observed (ie, some transcripts were regulated in more than one condition). In detail, 979 transcripts were regulated in response to IFX (99 upregulated, 880 downregulated), 99 transcripts were regulated in response to CZP (17 upregulated, 82 downregulated), 959 transcripts were regulated only by IFX (98 upregulated, 861 downregulated), 79 transcripts were regulated by CZP only (16 upregulated, 63 downregulated) and 20 transcripts were regulated by CZP and FIX (1 upregulated, 19 downregulated). A more detailed list of the regulated transcripts is presented in online supplementary table 2, while the 20 transcripts regulated by both CXP and IFX are presented in online supplementary table 5. The top 50 regulated genes for IFX only, IFX and CZP and for CZP only are presented in figure 1. Only among the IFXregulated transcripts was a cluster of apoptosis-associated transcripts detected, which confirms the pro-apoptotic action of IFX detected in previous studies. Analysis of this cluster revealed a downregulation of apoptosis-inhibitory genes (eg, CIAPIN1, $A P I 5)^{19} 20$ and an upregulation of apoptosis-promoting genes (eg, PDCD4, PDCD6, BTG1, BIRC4BP, BNIP3L) ${ }^{21-25}$ (table 1). Differential induction of pro-apoptotic and anti-apoptotic signalling events by IFX and CZP in THP-1 was validated in PBMCs by RT-PCR, MTS and Caspase Glo assays. As shown in 
Figure 1 Whole genome expression analysis. THP-1 cells, a human monocytic cell line, were stimulated with infliximab or certolizumab pegol (both $10 \mu \mathrm{g} / \mathrm{ml}$ ) for 6 and $24 \mathrm{~h}$ or were left untreated (control). Three different comparisons are presented: transcripts, regulated when comparing infliximab with control $(A)$, certolizumab pegol with control (B), and transcripts regulated by both stimuli (C). For (A) and (B) the top 50 regulated transcripts are presented (selected by fold change and significance). Columns represent samples while each row represents a transcript. Where no gene symbol was available, the public reference was listed in brackets. Transcripts are ordered according to their expression similarities (correlation). The heatmap displays relative expression intensities (z-score normalised). Arrows to the right of each heatmap group the transcripts into regulation categories.
A

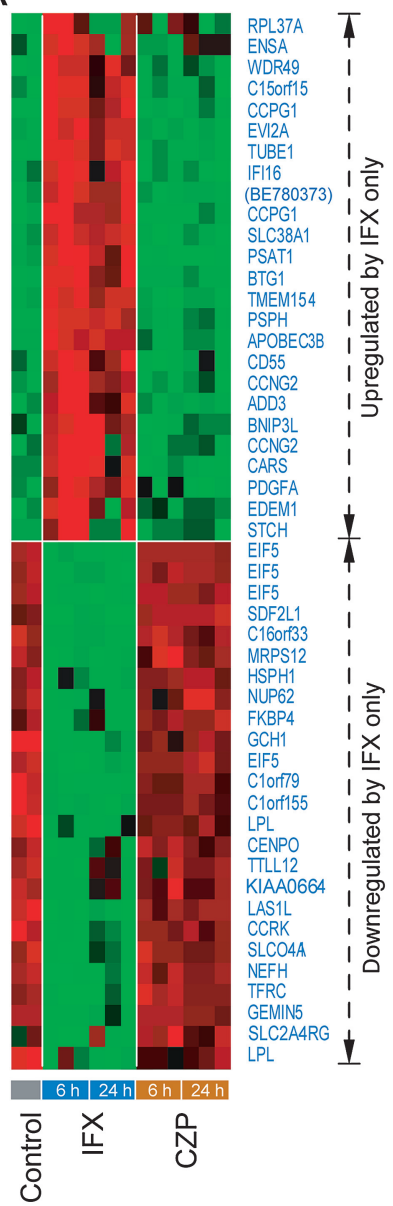

B

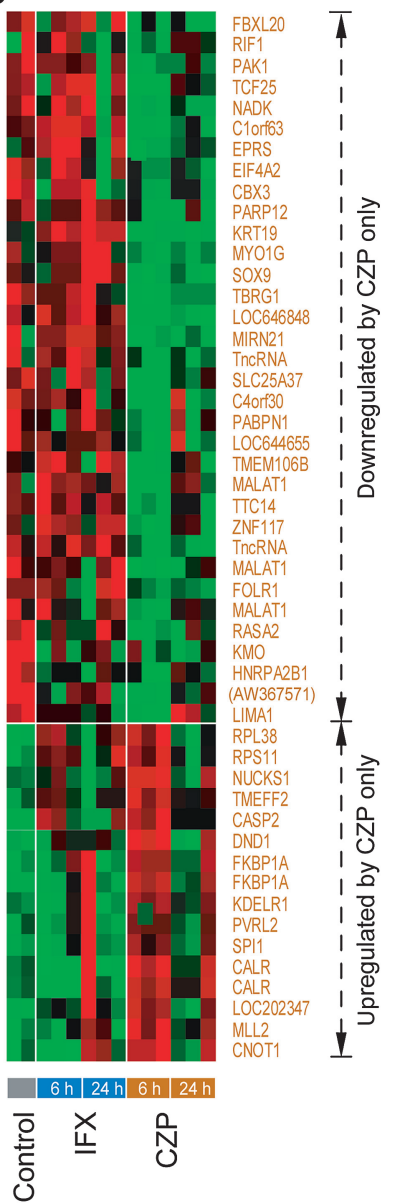

C

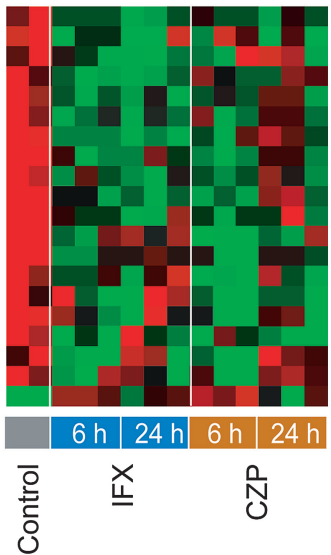

online supplementary figure 1, API5 was upregulated by CZP (6 and $24 \mathrm{~h}$ ) but not by IFX treatment (online supplementary figure 1A). Furthermore, MTS assays revealed that IFX led to a marked reduction of cell viability in THP-1 and PBMCs. Using this method, CZP also elicited a slight but significant reduction of cell viability in PBMCs, while no effect on THP-1 cells could be observed (online supplementary figure $1 \mathrm{~B}-\mathrm{D}$ ). Using a luminometric assay for caspase activation, IFX, but not CZP, activated caspases $3 / 7$ in both cell types (online supplementary figure $1 \mathrm{E}, \mathrm{F})$

Importantly, a signature of 20 shared transcripts was identified, which were significantly regulated by IFX and CZP (figure 1C). Among these, two were found to encode unknown proteins
(LOC284702, LOC440944) and two other putative transcripts were not covered by spliced ESTs (expressed sequence tags) corresponding to the reported oligonucleotide probe. Twelve of the remaining 16 transcripts could be categorised into the following main cellular processes: cell cycle regulation (PRDX6, NACA, UHMK1, C13orf25, GDF-1/LASS1), mRNA processing (RNPS1, SFRS7, HNRPA1, TncRNA), transcription activation and nuclear transport (KPNA3, HNRPA1, ANKRD12, ARHGEF19), whereas the last four transcripts are part of the ribosomal $60 \mathrm{~S}$ subunit (RPL17, RPL37A) or belong to the solute carrier family (SLC16A10 and SLC16A3) (online supplementary table 5).

To verify these results, cDNA was prepared from THP-1 and PBMCs stimulated with IFX or CZP. The mRNA data for THP-1 
Table 1 Overview of apoptosis-associated transcripts regulated by infliximab (IFX)

\begin{tabular}{lllll}
\hline Effect of IFX & Gene & Name & Function & Reference \\
\hline Downregulation & CIAPIN1 & $\begin{array}{l}\text { Cytokine-induced apoptosis } \\
\text { inhibitor 1 }\end{array}$ & Anti-apoptotic & 19 \\
& API5 & Apoptosis inhibitor 5 & Anti-apoptotic & 20 \\
Upregulation & $P D C D 4$ & Programmed cell death 4 & Anti-proliferative, pro-apoptotic & 21 \\
& PDCD6 & Programmed cell death 6 & Ca $^{2+}$ binding, pro-apoptotic & 23 \\
& BTG1 & B-cell translocation gene 1 & Pro-apoptotic, anti-proliferative & 24 \\
& BIRC4BP & XIAP associated factor 1 & Pro-apoptotic, antagonist of XIAP & 22 \\
& BNIP3L & BCL2/adenovirus E1B 19 kDa & Pro-apoptotic, target of p53 & 25 \\
& & interacting protein 3-like & & \\
\hline
\end{tabular}

BCL2, B-cell lymphoma 2; XIAP, X-linked inhibitor of apoptosis.

cells (GDF-1/LASS1, ARHGEF19, NACA, UHMK1 and PRDX6) and for PBMCs (c13orf25, UHMK1, ARHGEF19, KPNA3, NACA, $P R D X 6, R N P S 1)$ in RT-PCR experiments also reflected data received from microarray expression study (online supplementary figure 2A,C). To exclude the effects of IgG1 or pegylated structures, THP-1 cells were stimulated with irrelevant IgG1 or pegylated Fab fragment for $24 \mathrm{~h}$. cDNA was analysed by RTPCR with regard to GDF-1/LASS1 expression. No regulation could be observed (online supplementary figure $2 \mathrm{~B}$ ).

\section{GDF-1 is expressed ubiquitously in different tissues}

GDF-1/LASS1 was selected for follow-up, as the protein GDF-1 represents the only soluble factor in the list of commonly regulated transcripts. This renders the protein generally acces- sible to future neutralisation studies, for example, by specific antibodies. Moreover, GDF-1 belongs to the TGF $\beta$ superfamily, members of which have been broadly implicated both in the etiopathogenesis of IBD and as important mediators of the mechanisms of action (MoA) of anti-TNF compounds. ${ }^{8} 26$

$G D F-1$ is transcribed into a bicistronic mRNA together with LASS1, the human orthologue of longevity assurance factor 1 from Saccharomyces cerevisiae. In addition to the bicistronic transcript variant, a second monocistronic variant encoding only LASS1 has been identified (online supplementary figure 2C). Data for the Probe-ID $229448 \times$ at that only detects the monocistronic variant of LASS1 mRNA were compared with data received from the Probe-ID 206397_x_at that detects the bicistronic mRNA variant GDF-1/LASS1. It could be shown that only the bicistronic mRNA
Figure 2 Growth and differentiation factor 1 (GDF-1) expression analysis. (A) Human GDF-1 proprotein and GDF-1 mature protein. The presented models illustrate processing of GDF-1 precursor to yield mature protein. Homology models were generated using GDF-1 amino acid sequence (GenBank AAB94786.1) and SWISS-Model programme software. ${ }^{27}$ (B) GDF-1/ LASS1 upregulation in colonic biopsies from patients with Crohn's disease (CD). Real-time PCR was performed with cDNA derived from sigmoidal biopsies $(n=150)$. Medians of data for subgroups ( $H N n=30, C D$ ni $n=31$, $C D \_i n=29$, UC_ni=29, UC $i n=31$ ) are presented as black bars. ( $\bar{C})$ Western blot analysis of GDF-1 protein upregulation in colonic biopsies from patients with CD. Densitometric analysis of the blot was performed with ImageJ. (D) GDF-1-specific ELISA was performed with colonic biopsies from inflamed and non-inflamed tissue from patients with $C D$ and ulcerative colitis (UC) (each $n=5$ ). CD i, Crohn disease inflamed; $C D$ ni, Crohn's disease noninflamed; $\mathrm{UC}^{-} \mathrm{i}$, ulcerative colitis inflamed; $D C i$, diseased controls inflamed; HN, hospitalised normals; ${ }^{*} \mathrm{p} \leq 0.05 ;{ }^{*} \mathrm{p} \leq 0.01$.
A

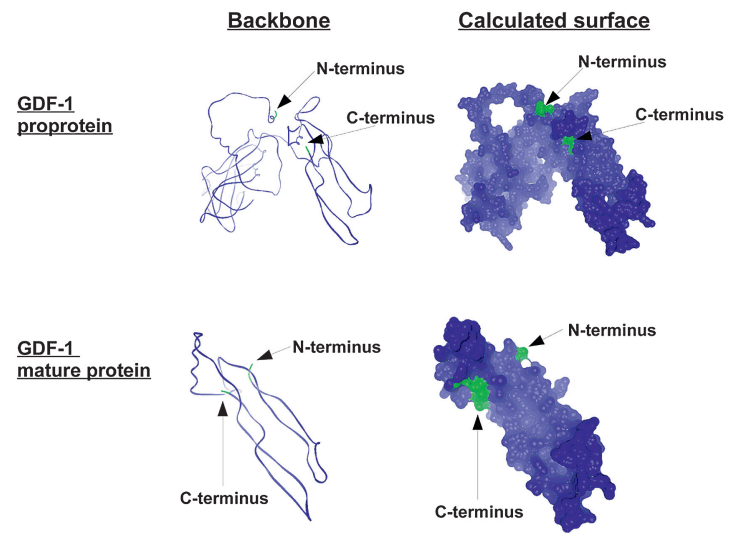

C
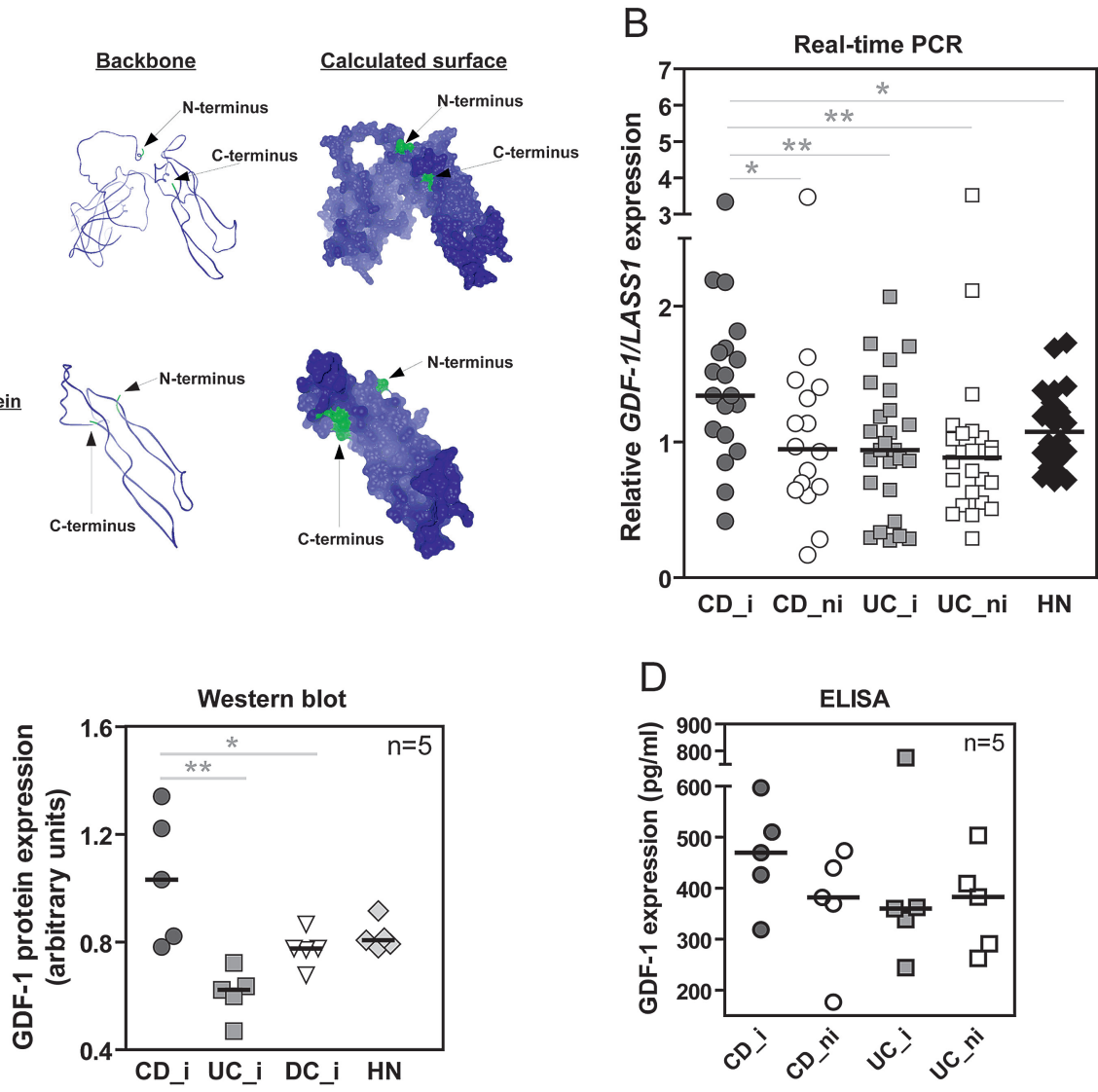

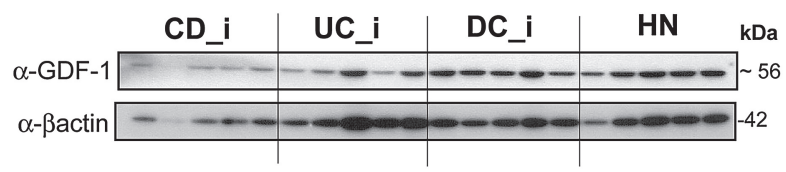


variant of GDF-1/LASS1 was regulated by IFX/CZP, whereas no alteration of LASS1 mRNA expression could be detected. Comparison of received data sets revealed a very low detection signal for Probe-ID 229448_x_at (online supplementary figure 2D).

cDNA from a human tissue panel was used for mRNA expression analysis of GDF-1/LASS1 in different tissues. GDF-1/ LASS1 transcript was ubiquitously expressed (online supplementary figure $3 \mathrm{~A}$ ) with highest expression in small intestine, brain, testis and skeletal muscles.

As GDF-1/LASS1 are translated from a single bicistronic mRNA, we investigated protein levels of GDF-1 and LASS1 in relevant cell lines to determine translation efficacy of the two putative ribosomal entry sites. GDF-1, which is initially translated as a proprotein and processed by proteolytic cleavage to yield the mature protein (figure 2A), was expressed in all examined cell lines with the highest expression in HEK293, HepG2 and Caco-2 (online supplementary figure 3B). Moderate protein expression was found in HeLa, SW480, HT-29 and THP1. While an unclear protein band, corresponding to the predicted molecular weight of LASS1 $(39 \mathrm{kDa})$, was found in cell lines, virtually no protein band was detectable in lysates from intestinal biopsies of $\mathrm{HN}$, patients with IBD and DC (online supplementary figure $3 \mathrm{~B}, \mathrm{C}$ ).

\section{GDF-1 expression is upregulated in inflamed biopsies from patients with CD}

We next investigated by RT-PCR whether GDF-1/LASS1 is differentially regulated in patients with $C D(n=35)$ or UC $(\mathrm{n}=50)$ compared with $\mathrm{HN}(\mathrm{n}=24)$. Normalisation of GDF-1/ LASS1 data against $\beta$-actin data and a statistical analysis indicated a significant upregulation in CD_inflamed samples compared with tissues from $\mathrm{HN}$ and patients with UC (figure 2B).

To verify the obtained results at the protein level, protein extracts isolated from colonic biopsies $(n=20)$ were applied to SDS-PAGE and immunoblotting. GDF-1 protein was upregulated in CD_inflamed samples when compared with UC_inflamed ( $\mathrm{p} \leq 0 . \overline{0} 1)$ and DC_inflamed ( $\mathrm{p} \leq 0.05)$ samples (figure $\overline{2} \mathrm{C}$ ). In an additional set of colonic biopsies taken from patients with CD and UC (each $n=10$ ) using ELISA we show a similar pattern of upregulation in inflamed tissue from patients with $\mathrm{CD}$ compared with CD non-inflamed and UC tissue (irrespective of inflammation state; figure 2D), although the findings do not reach formal significance levels.

\section{GDF-1 expression is regulated by TGF $\beta$-mediated signalling}

As previous findings demonstrate that $\mathrm{MTNF} \alpha$ ligation by antiTNF $\alpha$ agents induces elevation of TGF $\beta$ secretion, a putative influence of TGF $\beta$-mediated signalling transduction on GDF-1 expression was analysed. ${ }^{8}$

PBMCs were stimulated with IFX/CZP for 6 or $24 \mathrm{~h}$ or were left untreated and mRNA levels of TGF $\beta$ and GDF-1/LASS1 were determined by RT-PCR. A reciprocal time-dependent upregulation of TGF $\beta$ mRNA and downregulation for GDF-1/ $L A S S 1 \mathrm{mRNA}$ was observed (figure $3 \mathrm{~A}$ ). In contrast, stimulation of THP-1 monocytes and PBMCs with TGF $\beta$ for $12 \mathrm{~h}$ led to
Figure 3 Detection of influence of transforming growth factor $\beta$ (TGF $\beta$ )induced signal transduction on GDF-1/ LASS1 expression. (A) Inverse regulation of GDF-1/LASS1 and TGF $\beta$ by infliximab (IFX) and certolizumab pegol (CZP). Peripheral blood mononuclear cells (PBMCs) were stimulated with IFX or CZP (both $10 \mu \mathrm{g} / \mathrm{ml}$ ) for 6 or $24 \mathrm{~h}$. Real-time PCR (RT-PCR) experiments were performed with $\mathrm{CDNA}$ and sequence-specific primers. (B) Downregulation of GDF-1/LASS1 mRNA by recombinant human TGF $\beta$ (rhTGF $\beta$ ) signalling transduction. Stimulation of cells with rhTGF- $\beta$ was performed for $18 \mathrm{~h}$. mRNA expression was analysed by RT-PCR. (C) Western blot analysis of GDF-1 protein regulation by rhTGF $\beta$ signaling. THP-1 was stimulated with $\operatorname{rhTGF} \beta(1 \mathrm{ng} / \mathrm{ml}, 10 \mathrm{ng} / \mathrm{ml})$ for 1 and 4 h. (D) Reversion of IFX/CZP-induced effects by TGF $\beta$ blockade. THP-1 cells were stimulated with IFX and CZP (both $10 \mu \mathrm{g} / \mathrm{ml}$ ) for 6 and $24 \mathrm{~h}$ in the presence or absence of anti-TGF $\beta$ antibody $(1 \mu \mathrm{g} / \mathrm{ml})$. mRNA expression was analysed by RT-PCR. (E) TGF $\beta$ specific ELISA was performed with colonic biopsies from inflamed and noninflamed tissue from patients with Crohn's disease (CD) and ulcerative colitis (UC) (each $n=5$ ) as well as from hospitalised normals $(n=3)$. CD i, Crohn's disease inflamed; CD ni, Crohn's disease non-inflamed; DC_i, diseased controls inflamed; UC i, ulcerative colitis inflamed; GDF-1, growth and differentiation factor 1 ; HN, hospitalised normals; ${ }^{* *} \mathrm{p} \leq 0.01$.

E
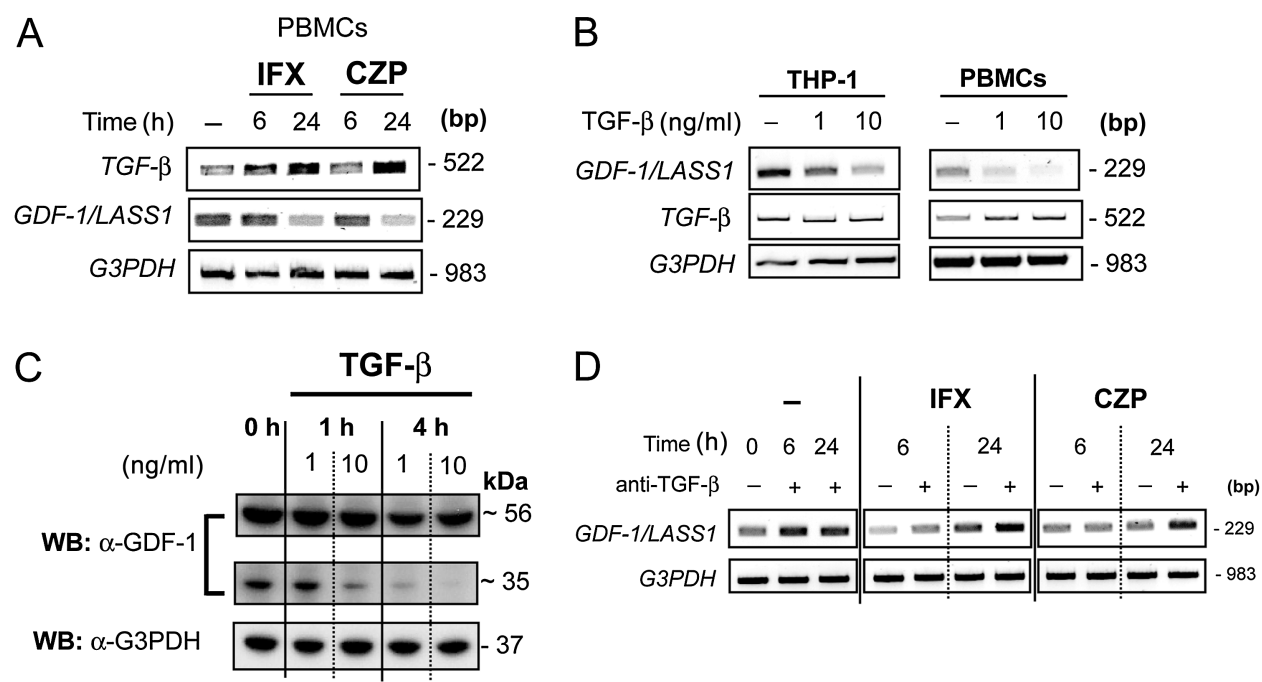
TGF $\beta$ ELISA

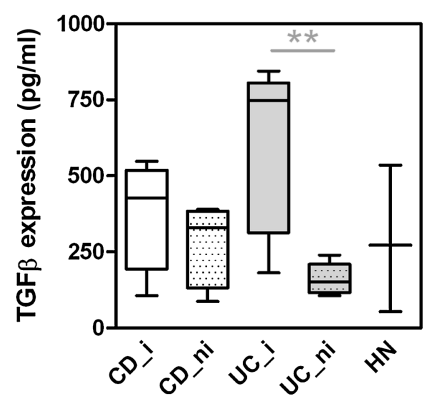


downregulation of GDF-1/LASS1 mRNA expression in a concentration-dependent manner. TGF $\beta$ mRNA expression was not altered by TGF $\beta$ stimulation (figure $3 \mathrm{~B}$ ). These findings were also reflected at the protein level for precursor and mature GDF-1 in THP-1 (figure 3C).

To further study the role of TGF $\beta$-mediated signalling transduction as a potential autocrine regulator of GDF-1 after $\mathrm{mTNF} \alpha$ ligation, we analysed GDF-1/LASS1 mRNA levels in THP-1 after stimulation with IFX and CZP for 6 or $24 \mathrm{~h}$ in the presence or absence of anti-TGF $\beta$ antibody. Pre-incubation of THP-1 with anti-pan TGF $\beta$ antibody $(1 \mu \mathrm{g} / \mathrm{ml})$ for $30 \mathrm{~min}$ prior to IFX stimulation enhanced GDF-1/LASS1 mRNA expression in a timedependent manner. The presence of anti-pan TGF $\beta$ antibody abolished the repressive effects of both anti-TNF $\alpha$ compounds on GDF-1/LASS1 mRNA expression levels (figure 3D).
TGF $\beta$ expression was analysed in inflamed and non-inflamed colonic biopsy samples from patients with CD and UC and from healthy normals by TGF $\beta$-specific ELISA experiments. Significant upregulated TGF $\beta$ expression was found in inflamed UC tissue compared with non-inflamed UC tissue. No regulation could be detected for CD tissue in comparison to UC or $\mathrm{HN}$ samples (figure $3 \mathrm{E}$ ).

GDF-1 acts as a proinflammatory cytokine by regulating IL-6 Finally, we studied the influence of recombinant human GDF-1 (rhGDF-1) protein on inflammatory responses in PBMCs.

Cells were stimulated for 6 and $24 \mathrm{~h}$ with various concentrations of rhGDF-1. mRNA expression of the proinflammatory cytokines $I L-6, I L-1 \beta$ and the inter-cellular adhesion molecule 1 (ICAM-1) was upregulated in a time-dependent manner with
A

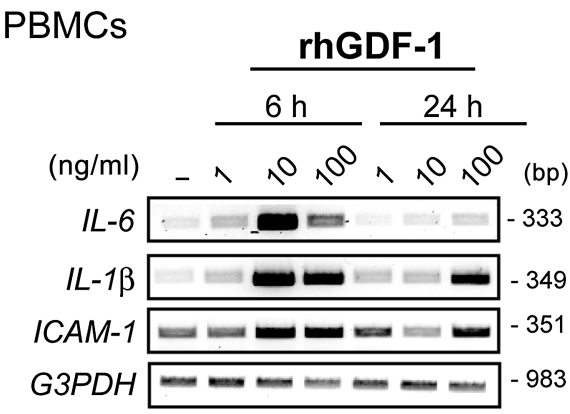

C

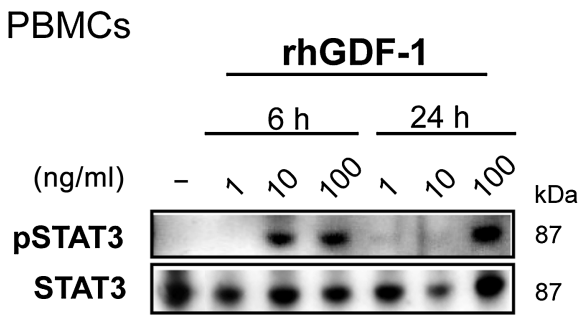

B
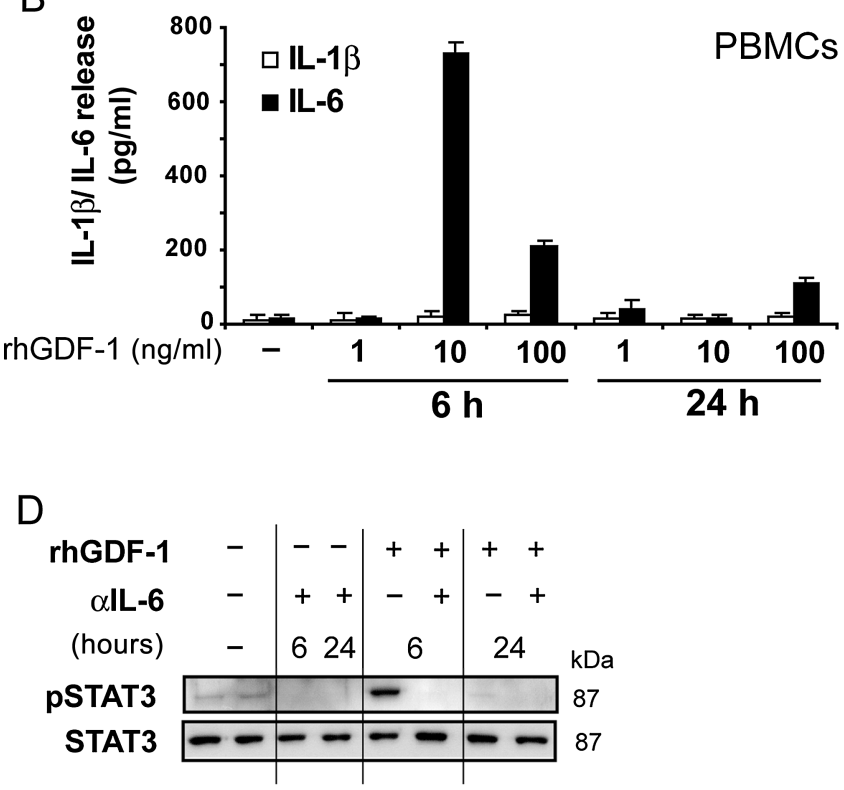

E

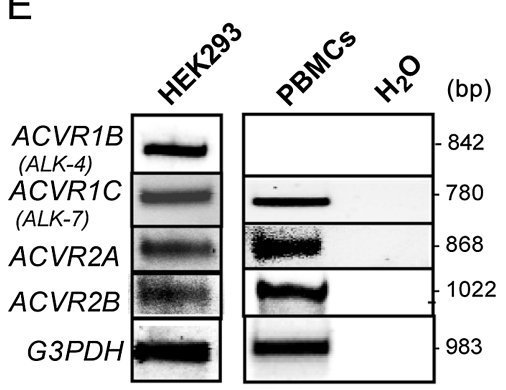

$\mathrm{F}$ PBMCs

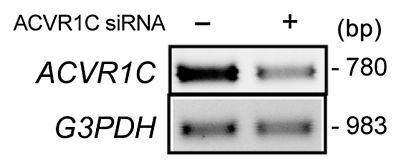

Ctrl. siRnA ACVR1C siRNA

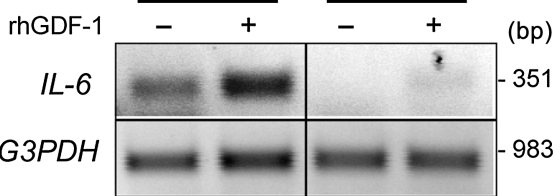

HEK293
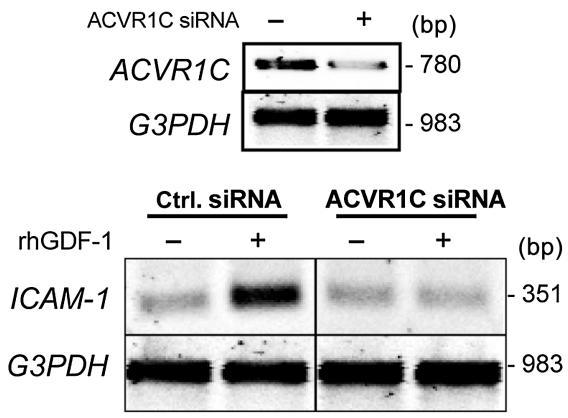

Figure 4 Regulation of interleukin $6(/ L-6)$ via recombinant human growth and differentiation factor 1 (rhGDF-1). Peripheral blood mononuclear cells (PBMCs) were stimulated with rhGDF-1 (1-100 ng/ml) for 6 or $24 \mathrm{~h}$ or left untreated before being analysed by (A) real-time PCR (RT-PCR), (B) IL-6 and IL-1 $\beta$-specific ELISA or (C) western blot. (D) Western blot analysis of signal transducer and activator of transcription 3 (STAT3) activation by rhGDF-1 depended on IL-6 signalling. PBMCs were stimulated with rhGDF-1 for 6 or $24 \mathrm{~h}$ in the presence or absence of anti-IL-6 antibody (1 $\mu \mathrm{g} / \mathrm{ml})$. (E) Expression analyses of ACVR1B, ACVR1C, ACVR2A or ACVR2B in PBMCs and HEK293T cells were performed by RT-PCR. All four receptors could be detected in both cell lines except for ACVR1B in PBMCs. (F) RNA interference-induced knockdown of ACVR1C. PBMCs (left panel) or HEK293T cells (right panel) were transfected with an ACVR1C-specific small interfering RNA (siRNA) or a negative control siRNA. Subsequently, cells were stimulated with rhGDF-1 $(10 \mathrm{ng} / \mathrm{ml})$ for $6 \mathrm{~h}$ or were left untreated. RT-PCR was performed using transcript-specific primers. ICAM-1, inter-cellular adhesion molecule 1. 
peaking after $6 \mathrm{~h}$ of stimulation (figure 4A). Upregulation of $I L-6$ transcript levels was accompanied by an increased IL-6 secretion as assessed by ELISA, whereas no secretion of mature IL-1 $\beta$ was observed (figure 4B).

To characterise signalling events underlying the proinflammatory effect of GDF-1 we analysed the activation of several transcription factors. While activation of transcription factor Smad2/3 was only induced after $6 \mathrm{~h}$ of stimulation of PBMCs with rhGDF-1 (online supplementary figure 4), we detected a strong activation of the transcription factor signal transducer and activator of transcription 3 (STAT3) as assessed by phospho-specific western blot (figure 4C).

As IL-6 activates STAT3 phosphorylation via binding to IL-6R and gp130, it was analysed whether the observed STAT3 phosphorylation depends on autocrine IL-6 secretion induced by rhGDF-1. PBMCs were stimulated with rhGDF-1 in the presence or absence of an anti-IL- 6 antibody for 6 and $24 \mathrm{~h}$. Stimulation with rhGDF-1 for $6 \mathrm{~h}$ induced activation of STAT3 that was completely prevented by pre-incubation of cells with anti-IL-6 antibody for 30 min prior to rhGDF-1 stimulation (figure 4D). To unravel which receptor is engaged by GDF-1 signalling, expression analyses of known GDF-1-specific receptors $A C V R 1 B$ and $A C V R 1 C$ as well as of the unspecific receptors $A C V R 2 A$ and $A C V R 2 B$ were performed by RT-PCR using PBMCs and HEK293 cells serving as an additional model system. As demonstrated in figure 4E, all four receptors were expressed in HEK293 cells, while in PBMCs expression of $A C V R 1 C, A C V R 2 A$ and $A C V R 2 B$ but not of $A C V R 1 C$ could be detected. Therefore, knockdown of ACVR1C in PBMCs and HEK293T cells was induced by an ACVR1C-specific siRNA before stimulation of cells for $6 \mathrm{~h}$ with $10 \mathrm{ng} / \mathrm{ml}$ rhGDF-1. Finally, mRNA expression of ACVR1C, IL-6 or ICAM-1 was analysed by RT-PCR. In both PBMCs and HEK293 cells, GDF-1 induced upregulation of $I L-6$ or $I C A M-1$ mRNA expression was prevented by RNA interference (RNAi)-mediated knockdown of $A C V R 1 C$ (figure $4 \mathrm{~F}$ ).

\section{Downregulation of GDF1/LASS1 expression by IFX therapy is restricted to IFX responders}

To underline the role of GDF-1 as an important mediator of MoA of IFX and CZP in vivo, we investigated GDF-1 levels using a microarray dataset from colonic biopsy samples of anti-TNF naïve patients with CD prior to and 1 week after IFX therapy. Data were categorised into responders and non-responders. Clinical responders to IFX were defined to be patients whose CDAI decreased at least 70 CDAI points after 1 week of IFX treatment. As presented in figure 5A, GDF-1/LASS1 was significantly downregulated after IFX therapy in IFX responders but not in IFX non-responders, whereas the proinflammatory marker transcript ICAM-1 only showed a moderate trend towards lower transcript levels (see figure $5 \mathrm{~B}$ ).

\section{DISCUSSION}

TNF $\alpha$ antagonists are able to bind to mTNF $\alpha$ and activate a physiological reverse signalling cascade. We investigated transcriptome regulation by two TNF $\boldsymbol{\alpha}$-binding molecules that are therapeutically active in CD. By determining the communality in regulatory mechanisms elicited by IFX and CZP we aimed to uncover essential molecular principles of MoA triggered by these two agents.

A systematic microarray-based expression analysis in THP-1 demonstrated that signalling of IFX and CZP, respectively, induces distinctly different transcriptomal responses. Commonalities include downregulation of transcripts involved in cell cycle progression. This finding corresponds to previous studies in
A

IFX responders

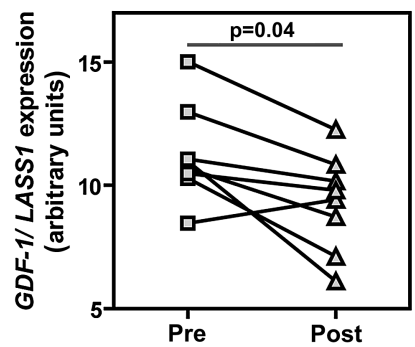

B
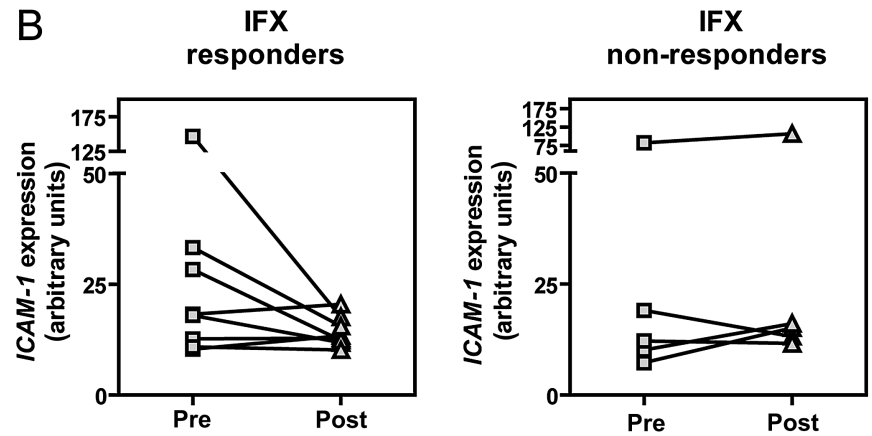

Figure 5 Regulation of GDF-1/ LASS1 by infliximab (IFX) therapy of patients with Crohn's disease (CD). cDNA from CD colonic biopsy samples collected prior and after IFX treatment were analysed by microarray analysis. (A) GDF-1/LASS1 expression (Probe Set ID 229448 at) was significantly downregulated after IFX treatment only in responders $(n=8)$ but not in non-responders $(n=5)$. (B) Inter-cellular adhesion molecule 1 (ICAM-1) (Probe Set ID 202637_s at) expression was also found to be downregulated in responders $(n=8)$ but not in nonresponders $(n=5)$ after IFX treatment but failed to reach statistical significance. GDF-1, growth and differentiation factor 1.

which IFX treatment was connected to inhibition of proliferative processes and the induction of cell cycle arrest in different subsets of human cells. ${ }^{26}{ }^{28}$ Both molecules have also been found to interfere with the nuclear factor $\kappa \mathrm{B}(\mathrm{NF}-\mathrm{\kappa} \mathrm{B})$ pathway or other transcriptional activators to diminish a sustained transcription activity as detected in active CD. ${ }^{29}$ Suppression of sustained NF$\kappa \mathrm{B}$ activation in intestinal biopsies of patients with $\mathrm{CD}$ has been previously shown after medical treatment with IFX that induced upregulation of the NF- $\kappa \mathrm{B}$ inhibitor proteins $I \kappa \mathrm{B} \alpha$ and $I \kappa \mathrm{B} \gamma$. $^{2} 30$ The data further suggest a link of IFX and CZP to the control of pre-mRNA processing and transport. Currently, little is known about inflammatory conditions and pre-mRNA splicing events. However, alterations in the morphology of nuclear speckles and therefore pre-mRNA splicing has been detected during inflammatory stimulation of colonic epithelial cell lines ${ }^{31}$ and a first report has shown that splicing patterns may be systematically altered in IBD. ${ }^{32}$ In conclusion, IFX and CZP target fundamental processes (cell cycle, transcription activation, pre-mRNA processing) most likely through $\mathrm{mTNF} \alpha$ reverse signalling that are pivotally involved in perpetuation of chronic inflammatory responses in $\mathrm{CD}$.

Among the shared transcripts that were regulated by both anti-TNF $\alpha$ compounds, we selected the downregulated bicistronic transcript GDF-1/LASS1 for a detailed functional follow-up.

In the present study, we detected moderate expression levels for GDF-1/LASS1 in the adult colon and high constitutive expression in the adult small intestine. We demonstrate a highly significant upregulation of mRNA levels as well as a tendency 
for upregulation of protein levels of the TGF $\beta$ superfamily member GDF-1 in the inflamed colonic mucosa of patients with $\mathrm{CD}$. While the reduced dynamics of the observed GDF-1 regulation on the protein level may in part be explained by the fact that secreted proteins are sometimes harder to detect in complex intestinal tissue samples, the findings still suggest a potential role of GDF-1 in inflammatory processes in CD.

Furthermore, our data point to a negative correlation of expression levels of GDF-1 and the main family member TGF $\beta$ in monocytic cells (ie, THP-1 and PBMCs). It is generally accepted that inflammatory signalling events induced by proinflammatory cytokines like TNF $\alpha$ and IL- 6 are counteracted by the anti-inflammatory cytokine TGF $\beta$. By binding to its receptors (TGF $\beta$ RII and activin receptor-like kinases $1 / 2 / 5$ ), TGF $\beta$ activates main downstream targets, for example Smad2/3 and MAPKs, to induce antiproliferative processes. ${ }^{33}$ However, TGF $\beta$ has been linked to some cancer types and autoimmune diseases. ${ }^{33} 34$ This study is the first to report in monocytes that ACVR1C (ALK-7)-mediated signalling transduction triggered by GDF-1 leads to a significant induction of proinflammatory cytokines and indirect activation of the transcription factor STAT3. Absence of IL-6 secretion after $24 \mathrm{~h}$ of stimulation with GDF-1 might point to a complex network of cellular signalling cascades, such as initiation of negative feedback loops, that controls excessive activation of signalling pathways and in that way counteracts with GDF-1 signalling cascade. It must be further noted that it could not be excluded that the second GDF1-specific receptor ACVR1B might play an important role in GDF-1 signalling in other cellular contexts. We identified the proinflammatory cytokine IL-6 to be a major autocrine amplifier of GDF-1 signalling, as STAT3 activation downstream of GDF-1 could be prevented by a blocking IL- 6 antibody.

IL-6 is a pleiotropic cytokine that induces inflammatory and proliferative processes. ${ }^{35}$ Sustained IL-6 production and there- with gp130-mediated activation of STAT3 have been linked to proliferative and survival effects in normal and premalignant intestinal epithelial cells and therefore are involved in tumourigenesis. ${ }^{36}$ Several publications also discussed the function of IL-6 trans-signalling via gp130 and STAT3-induced resistance to apoptosis in IBD, ${ }^{37}$ while blocking of membrane-bound and sIL$6 \mathrm{R}$ has been found to diminish disease activity in patients with $\mathrm{CD}^{38}$

In intestinal epithelial cells, TGF $\beta$ has been shown to inhibit the IL-6/STAT3 signalling pathway via Smad2 activation. ${ }^{39}$ Activation of the TGF $\beta$ downstream target Smad2/3 is blocked by the upregulation of its inhibitor Smad7.$^{40}$ Vice versa, in murine models of colitis, treatment with Smad7 antisense oligonucleotides initiates restoration of TGF $\beta$ signalling and therefore diminishes inflammation. ${ }^{41}$ Hyperactivation of STAT3 in murine models is accompanied by the activation of Smad7 $7^{42}$ and thus prevents anti-inflammatory signal transduction by TGF $\beta$.

We further detected in this study that both IFX and CZP suppress the expression of GDF-1 via a TGF $\beta$-dependent autocrine signalling loop in vitro. However, TGF $\beta$-dependent paracrine signalling cannot be excluded. Previous studies also linked the anti-inflammatory action of TNF $\alpha$ antagonists, in particular IFX, to the secretion of TGF $\beta^{8}{ }^{26}$ and interestingly to the inactivation of STAT3 in activated intestinal CD4+ T cells. ${ }^{43}$ Hence, it might be speculated that anti-TNF $\alpha$ treatment in active CD may reverse the imbalance between Smad2/3 and Smad7 by increasing TGF $\beta$ release, therefore allowing TGF $\beta$ to completely unfold its anti-inflammatory action (figure 6). It must be noted that a complex regulation of mucosal TGF $\beta$ levels has been described in IBD in different cell types ${ }^{40}$ On the whole biopsy level, some studies demonstrated excessive production of TGF $\beta$ in inflamed IBD tissues, while others suggested lesser TGF $\beta$ secretion by lamina propria mononuclear cells (LMPCs) isolated
Figure 6 Model of membrane-bound tumour necrosis factor $\alpha$ (mTNF $\alpha$ ) reverse signalling via infliximab (IFX)/ certolizumab pegol (CZP). TNF $\alpha$ antagonists induce mTNF $\alpha$ reverse signalling leading to mitogen-activated protein kinase (MAPK) activation and enhanced transforming growth factor $\beta$ (TGF $\beta$ ) secretion. TGF $\beta$ in turn exerts anti-inflammatory action through triggering Smad2/3-dependent downregulation of proinflammatory mediators like growth and differentiation factor 1 (GDF-1) and interleukin 6 (IL-6). PEG, pegylated; pMAPKs, phosphorylated MAPKs; pSmad2/3, phosphorylated Smad2/3.

\section{Anti-TNF $\alpha$}

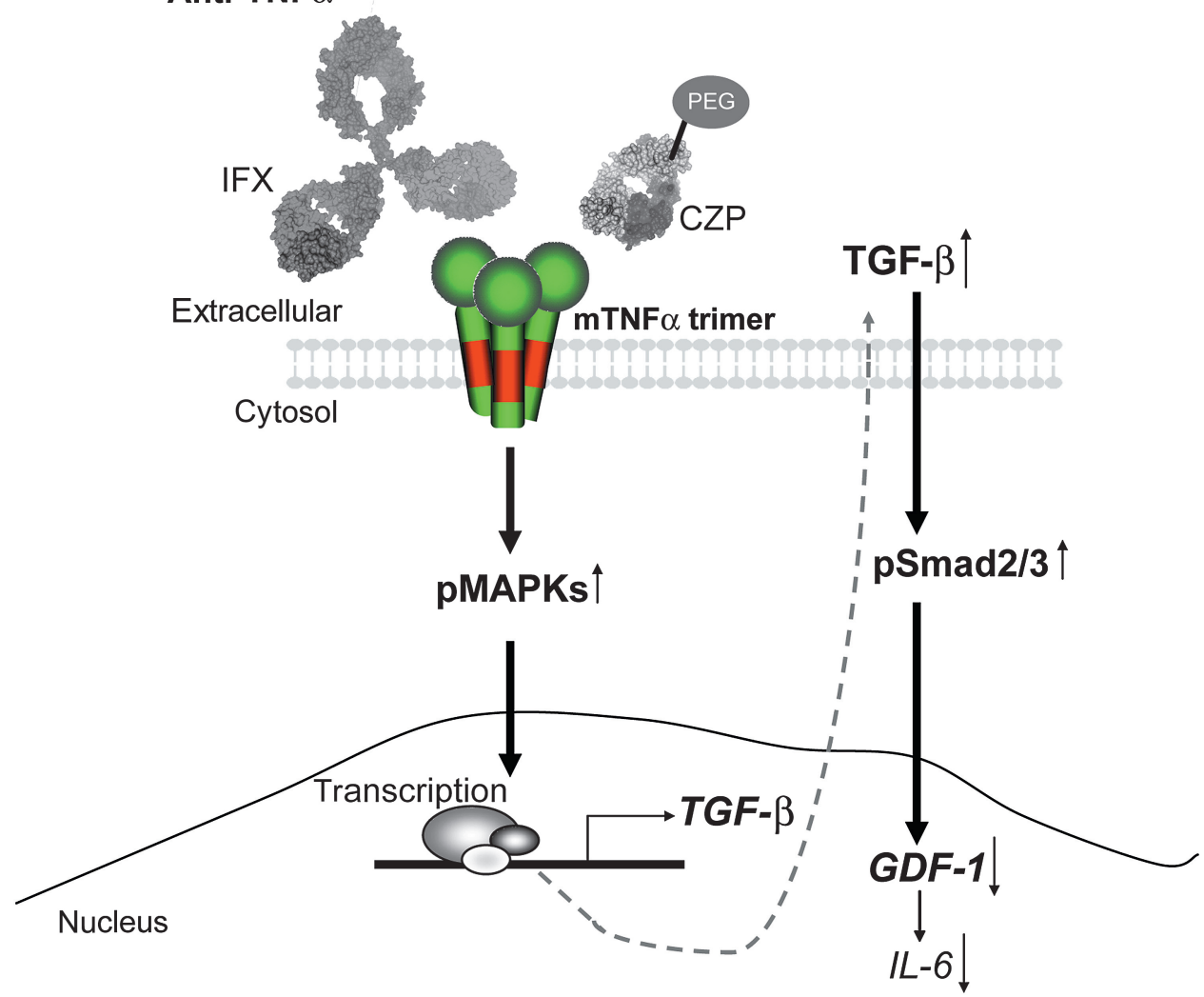


from patients with CD when compared with UC samples. ${ }^{40} 44$ Interestingly, whereas we detected a significant upregulation of GDF-1 levels in mucosal biopsies in IFX responders, we observed no significant regulation in TGF $\beta$ expression after IFX treatment in the same patients (data not shown). Taken together with the fact that TGF $\beta$ levels may not reflect the biological activity of the cytokine in the tissue (eg, as it has to be activated by proteolytic cleavage or due to Smad7 dysregulation) a more detailed investigation of cell-type specific regulatory events of this pathway after anti-TNF therapy is still warranted. In this study we have based the responder/non-responder categorisation on changes in a validated clinical activity index (CDAI) that has been used in previous anti-TNF clinical trials. ${ }^{3}{ }^{14}$ Given the role of TGF $\beta$ in regeneration and tissue repair, it will be interesting to study the detailed role of GDF- 1 and TGF $\beta$ in mucosal healing in this setting. Our functional data suggest that GDF-1 may serve as an additional layer of complexity that has to be taken into account.

In conclusion, this study for the first time presents converging alleys of signalling networks triggered by the TNF $\alpha$ antagonists IFX and CZP. One of their main targeted cellular processes seems to be the regulation of cell cycle and proliferation. Here, we reveal a completely new role of the TGF $\beta$ superfamily member GDF-1 as a proinflammatory cytokine involved in inflammatory processes. It might be hypothesised that, in vivo, GDF-1 induces chronic inflammation as found in CD via sustained activation of the IL-6/STAT3 pathway that may further suppresses the antiinflammatory effects of TGF $\beta$ and hence promotes ongoing proliferation of cells. ${ }^{36}{ }^{42}$ Furthermore, GDF-1 is downregulated in responders, but not in non-responders after IFX therapy. Accordingly, the mechanism of action of IFX and CZP in CD might in part be explained by interfering with GDF-1 and hence IL- 6 production via a TGF $\beta$-dependent autocrine signalling loop initiated by $\mathrm{mTNF} \alpha$ reverse signalling. Studying the exact physiological role of GDF-1 in complex inflammatory processes in vivo may answer the question of whether this proinflammatory molecule could be a novel promising target in the therapy of patients with $\mathrm{CD}$.

\begin{abstract}
Acknowledgements The authors thank the patients without whom this study would not have been possible. The endoscopy staff and the physicians Tanja Kaacksteen, Dorina Oelsner, Yasmin Brodtmann and Melanie Schlapkohl are gratefully acknowledged for their expert technical assistance. We thank Nancy Mah and the other authors of the IFX response study for providing GDF-1 mRNA expression data. Andrew Nesbitt (UCB) is acknowledged for his kind gift of pegylated Fab.
\end{abstract}

Contributors SD, AT, PR and SS designed the study. SN, TK, RH, CS, PCR and SS were involved in the recruitment and collection of samples. SD, RH and NG performed all laboratory work. SD, RH, AT and PR performed data analysis. Interpretation of data and writing of the manuscript were done by SD, RH, AT and PCR. SJ, JG, SR-J and SS proofread the manuscript prior to submission.

Funding This work was supported by an unrestricted grant of UCB S.A. (Brussels, Belgium) and the clusters of excellence Inflammation at Interfaces and The Future Ocean and the SFB877 (to SR-J, PCR and SS).

Competing interests Individual conflicts of interest are stated in the ICJME forms for SS, SN, TK, SRJ and PR.

Ethics approval Ethics approval was provided by the local ethics committee.

Provenance and peer review Not commissioned; externally peer reviewed.

Data sharing statement The authors agree to share the data.

\section{REFERENCES}

1. Schreiber S, Nikolaus S, Hampe J, et al. Tumour necrosis factor alpha and interleukin 1beta in relapse of Crohn's disease. Lancet 1999:353:459-61.

2. Nikolaus S, Raedler A, Kuhbacker T, et al. Mechanisms in failure of infliximab for Crohn's disease. Lancet 2000;356:1475-9.
3. Hanauer SB, Feagan BG, Lichtenstein GR, et al. Maintenance infliximab for Crohn's disease: the ACCENT I randomised trial. Lancet 2002;359:1541-9.

4. Black RA, Rauch CT, Kozlosky CJ, et al. A metalloproteinase disintegrin that releases tumour-necrosis factor-alpha from cells. Nature 1997; 385:729-33.

5. Smith CA, Farrah T, Goodwin RG. The TNF receptor superfamily of cellular and viral proteins: activation, costimulation, and death. Cell 1994;76:959-62.

6. Eissner G, Kirchner $\mathrm{S}$, Lindner $\mathrm{H}$, et al. Reverse signaling through transmembrane TNF confers resistance to lipopolysaccharide in human monocytes and macrophages. $J$ Immunol 2000;164:6193-8.

7. Waetzig GH, Rosenstiel P, Nikolaus S, et al. Differential p38 mitogen-activated protein kinase target phosphorylation in responders and nonresponders to infliximab. Gastroenterology 2003;125:633-4; author reply 635-6.

8. Waetzig GH, Rosenstiel P, Arlt A, et al. Soluble tumor necrosis factor (TNF) receptor-1 induces apoptosis via reverse TNF signaling and autocrine transforming growth factor-beta1. FASEB J 2005;19:91-3.

9. Van den Brande JM, Braat $\mathrm{H}$, van den Brink GR, et al. Infliximab but not etanercept induces apoptosis in lamina propria T-lymphocytes from patients with Crohn's disease. Gastroenterology 2003;124:1774-85.

10. Sandborn WJ, Hanauer SB, Katz S, et al. Etanercept for active Crohn's disease: a randomized, double-blind, placebo-controlled trial. Gastroenterology 2001;121:1088-94

11. Nesbitt A, Fossati G, Bergin M, et al. Mechanism of action of certolizumab pegol (CDP870): in vitro comparison with other anti-tumor necrosis factor alpha agents. Inflamm Bowel Dis 2007;13:1323-32.

12. Van den Brande JM, Koehler TC, Zelinkova Z, et al. Prediction of antitumour necrosis factor clinical efficacy by real-time visualisation of apoptosis in patients with Crohn's disease. Gut 2007;56:509-17.

13. Schreiber S, Rutgeerts $\mathrm{P}$, Fedorak RN, et al. A randomized, placebo-controlled tria of certolizumab pegol (CDP870) for treatment of Crohn's disease. Gastroenterology 2005; 129:807-18.

14. Targan SR, Hanauer SB, van Deventer SJ, et al. A short-term study of chimeric monoclonal antibody CA2 to tumor necrosis factor alpha for Crohn's disease. Crohn's Disease cA2 Study Group. N Engl J Med 1997;337:1029-35.

15. Waetzig GH, Seegert D, Rosenstiel P, et al. p38 mitogen-activated protein kinase is activated and linked to TNF-alpha signaling in inflammatory bowel disease. J Immunol 2002; 168:5342-51

16. Mah N, Pierrou S, Hammer M, et al. Molecular mechanisms of infliximab response in Crohn's disease (CD) patients. Gastroenterology 2007;132:A555-6.

17. Hasler R, Begun A, Freitag-Wolf $\mathrm{S}$, et al. Genetic control of global gene expression levels in the intestinal mucosa: a human twin study. Physiol Genomics 2009; 38:73-9.

18. Edgar R, Domrachev M, Lash AE. Gene Expression Omnibus: NCBI gene expression and hybridization array data repository. Nucleic Acids Res 2002;30:207-10.

19. Li X, Hong L, Zhao Y, et al. A new apoptosis inhibitor, CIAPIN1 (cytokine-induced apoptosis inhibitor 1), mediates multidrug resistance in leukemia cells by regulating MDR-1, Bcl-2, and Bax. Biochem Cell Biol 2007;85:741-50.

20. Morris EJ, Michaud WA, Ji JY, et al. Functional identification of Api5 as a suppressor of E2F-dependent apoptosis in vivo. PLoS Genet 2006;2:e196.

21. Goke R, Gregel C, Goke A, et al. Programmed cell death protein 4 (PDCD4) acts as a tumor suppressor in neuroendocrine tumor cells. Ann N Y Acad Sci 2004; 1014:220-1.

22. Straszewski-Chavez SL, Visintin IP, Karassina N, et al. XAF1 mediates tumor necrosis factor-alpha-induced apoptosis and X-linked inhibitor of apoptosis cleavage by acting through the mitochondrial pathway. J Biol Chem 2007;282:13059-72

23. Tarabykina S, Mollerup J, Winding P, et al. ALG-2, a multifunctional calcium binding protein? Front Biosci 2004; 9:1817-32.

24. Lee $\mathbf{H}$, Cha S, Lee MS, et al. Role of antiproliferative B cell translocation gene-1 as an apoptotic sensitizer in activation-induced cell death of brain microglia. J Immuno 2003;171:5802-11.

25. Fei $\mathbf{P}$, Wang W, Kim SH, et al. Bnip3L is induced by p53 under hypoxia, and its knockdown promotes tumor growth. Cancer Cell 2004;6:597-609.

26. Gunnlaugsdottir B, Skaftadottir I, Ludviksson BR. Naive human T-cells become nonresponsive towards anti-TNFalpha (infliximab) treatment in vitro if co-stimulated through CD28. Scand J Immunol 2008;68:624-34.

27. Arnold K, Bordoli L, Kopp J, et al. The SWISS-MODEL workspace: a web-based environment for protein structure homology modelling. Bioinformatics 2006;22:195-201.

28. Mitoma H, Horiuchi T, Hatta N, et al. Infliximab induces potent anti-inflammatory responses by outside-to-inside signals through transmembrane TNF-alpha. Gastroenterology 2005;128:376-92

29. Schreiber S, Nikolaus S, Hampe J. Activation of nuclear factor kappa B inflammatory bowel disease. Gut 1998;42:477-84.

30. Guidi L, Costanzo M, Ciarniello M, et al. Increased levels of NF-kappaB inhibitors (IkappaBalpha and IkappaBgamma) in the intestinal mucosa of Crohn's disease patients during infliximab treatment. Int J Immunopathol Pharmacol 2005; 18:155-64.

31. Zhu YQ, Lu Y, Tan XD. Monochloramine induces reorganization of nuclear speckles and phosphorylation of SRp30 in human colonic epithelial cells: role of protein kinase C. Am J Physiol Cell Physiol 2003:285:C1294-303.

32. Hasler R, Kerick M, Mah N, et al. Alterations of pre-mRNA splicing in human inflammatory bowel disease. Eur J Cell Biol 2011;90:603-11. 
33. Moustakas A, Pardali K, Gaal A, et al. Mechanisms of TGF-beta signaling in regulation of cell growth and differentiation. Immunol Lett 2002;82:85-91.

34. Gordon KJ, Blobe GC. Role of transforming growth factor-beta superfamily signaling pathways in human disease. Biochim Biophys Acta 2008;1782:197-228.

35. Rose-John S, Mitsuyama K, Matsumoto S, et al. Interleukin-6 trans-signaling and colonic cancer associated with inflammatory bowel disease. Curr Pharm Des 2009:15:2095-103.

36. Grivennikov S, Karin E, Terzic J, et al. IL-6 and Stat3 are required for survival of intestinal epithelial cells and development of colitis-associated cancer. Cancer Cell 2009;15:103-13.

37. Atreya R, Neurath MF. Signaling molecules: the pathogenic role of the IL-6/STAT-3 trans signaling pathway in intestinal inflammation and in colonic cancer. Curr Drug Targets 2008:9:369-74.

38. Ito H, Takazoe M, Fukuda $\mathrm{Y}$, et al. A pilot randomized trial of a human antiinterleukin-6 receptor monoclonal antibody in active Crohn's disease. Gastroenterology 2004;126:989-96; discussion 947.
39. Walia B, Wang L, Merlin D, et al. TGF-beta down-regulates IL-6 signaling in intestinal epithelial cells: critical role of SMAD-2. Faseb J 2003;17:2130-2.

40. Monteleone G, Boirivant M, Pallone F, et al. TGF-beta1 and Smad7 in the regulation of IBD. Mucosal Immunol 2008:1(Suppl 1):S50-3.

41. Boirivant M, Pallone F, Di Giacinto C, et al. Inhibition of Smad7 with a specific antisense oligonucleotide facilitates TGF-beta1-mediated suppression of colitis. Gastroenterology 2006;131:1786-98.

42. Jenkins BJ, Grail D, Nheu T, et al. Hyperactivation of Stat3 in gp130 mutant mice promotes gastric hyperproliferation and desensitizes TGF-beta signaling. Nat Med 2005; 11:845-52

43. Rosenstiel P, Agnholt J, Kelsen J, et al. Differential modulation of p38 mitogen activated protein kinase and STAT3 signalling pathways by infliximab and etanercept in intestinal T cells from patients with Crohn's disease. Gut 2005;54:314-15; author reply 316.

44. Del Zotto B, Mumolo G, Pronio AM, et al. TGF-beta1 production in inflammatory bowel disease: differing production patterns in Crohn's disease and ulcerative colitis. Clin Exp Immunol 2003;134:120-6. 